\title{
Toll-like receptors revisited; a possible role for TLR1 in lupus nephritis
}

Several studies in systemic lupus erythematosus (SLE) have shown a possible role of endosomal toll-like receptors (TLRs) in lupus nephritis (LN), but the role of those interacting with ligands in the plasma membrane remains unclear. ${ }^{1}$ Herein, we revisit the genetic contribution of TLRs in SLE inspired by a patient with LN who carries a rare TLR1 variant.

We analysed coding and regulatory regions of the TLR1-10 genes in 855 patients with SLE (online supplemental data 1). Six variants (rs142003616, rs76600635, rs72493538, rs41305843, rs113706342, rs41311400) within TLR1, one (rs10006364) within TLR2, one (rs79088436) within TLR5 and two (rs55695972, rs117985012) within TLR6 were significantly enriched in LN but only rs142003616 (TLR1) remained significant after Bonferroni correction $(\mathrm{p}<0.039$, online supplemental table 1). To assess its biological significance, we employed in-silico functional annotation. The calculated deleteriousness score, CADD PHRED, for rs142003616 (5.56) points at the variant's potential functional importance. The rare risk allele is predicted to create a strong binding site for the core binding factor $(\mathrm{CBF}){ }^{2} \mathrm{CBF}$, also known as runt-related transcription factors (RUNX), are also associated with SLE, psoriasis and rheumatoid arthritis. ${ }^{3}$ To evaluate rs142003616 functional potential, we lastly performed a reporter assay that demonstrated a significantly higher expression of the reporter with the $G$ allele in Jurkat $(\mathrm{p}<0.0001)$ and Daudi cells $(\mathrm{p}<0.001)$, and a strong enhancer potential without allelic difference in THP-1 (figure 1).

Of interest, despite the higher prevalence of proliferative LN overall (215 of $292 \mathrm{LN}, 75 \%$ ), it was less associated with rs142003616 in comparison to membranous $\mathrm{LN}$ ( $p=0.047$, Fisher's exact test). Table 1 summarises the characteristics of patients with LN carrying the minor allele of rs142003616. One of them was a 39-year-old woman (\#6 table 1) admitted 
A

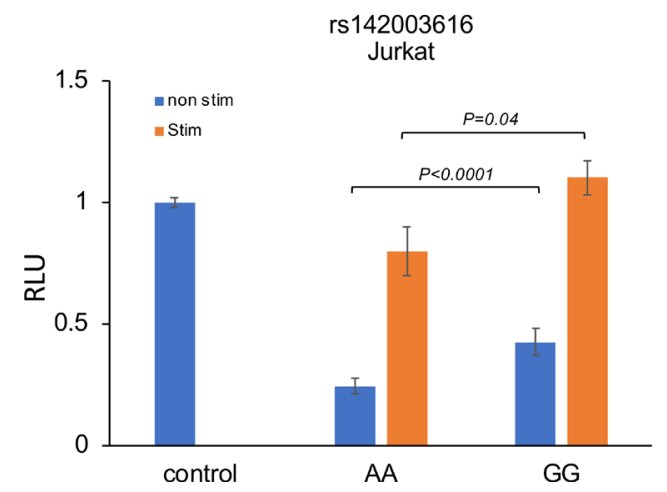

B

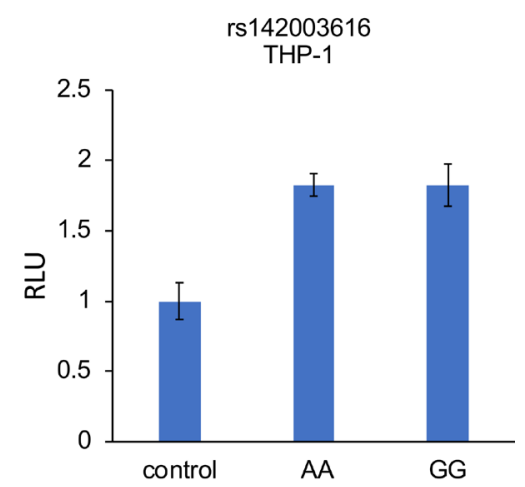

Figure 1 DNA fragments of 160 bp length with the variant in the middle were synthesised and cloned into pGL4.26 vector. Jurkat cells were transfected with reporter constructs containing different alleles of rs142003616 (A). Cells were left unstimulated for 48 hours or stimulated (stim) with PMA and ionomycin for 16 hours before harvesting. Protein lysates were assayed by the dual-reporter assay (Promega). Unpaired t-test was used for analysis of allelic difference. Similar low transcriptional levels and statistically significant allelic difference was detected upon transfection of Daudi cells (not shown). In THP-1 cells (B), the constructs show enhancer potential without allelic difference. Bars represent mean values $+/$-SEM. Non-stim, non-stimulated; RLU, relative light units.

to the hospital with prolonged fever $\left(39^{\circ} \mathrm{C}\right)$, headache, nonproductive cough, rash, leucopenia, high CRP $(78 \mathrm{mg} / \mathrm{L})$, microscopic haematuria and pyuria. Because of sinusitis and interstitial pneumonitis confirmed by chest tomography, the patient received doxycycline, and the fever and cough slowly disappeared, as did rash. Due to positive ANA (1/400), and persistence of haematuria, she was referred to the rheumatology department. The laboratory results showed dsDNA $(1 / 40)$, decreased classical complement function $(23 \%$ of normal; (N: 80\%-120\%)), low C4, anaemia, proteinuria $(0.4 \mathrm{gr} / \mathrm{d})$ and haematuria. Her diagnosis was confirmed with SLE after immunofluorescent staining of her renal biopsy resulted in WHO Class $\mathrm{Vb} \mathrm{LN}$, although light microscopy result demonstrated postinfectious glomerulonephritis. She went into remission with hydroxychloroquine, prednisone and enalapril for 7 years. Due to uprising proteinuria (up to $1 \mathrm{gr} / \mathrm{d}$ ), rebiopsy was performed, which demonstrated WHO Class IIb. We calculated her polygenic risk score (PRS), which was normal, 8.27. ${ }^{4}$ Our patient's history commencing with symptomatic infection, low PRS, which was against the general observation in LN, besides recovering to WHO class IIb without immunosuppressive therapy intrigued us and led to hypothesise that variants within TLR genes might contribute to the development or progression of LN.

Growing evidence highlights the role of podocytes in LN, not only as an integral part of kidney filtration barrier, but also their active involvement in immune-mediated kidney injury. ${ }^{5}$ Podocytes constitutively express TLR1-6 and TLR8, respond to TLR ligands with proinflammatory cytokine release, activation of type I IFN signalling, and, ultimately, podocyte injury with proteinuria. ${ }^{6}$ While innate immune responses play a central role in podocyte injury, evidence suggests that podocyte injury can initiate kidney damage in LN. ${ }^{5}$ We identified a rare variant associated with $\mathrm{LN}$, which affects TLR1 gene expression and might exert its effect via podocytes and immune cells. In conclusion, exogenous TLR ligands might contribute to the development of $\mathrm{LN}$, rare polymorphisms in this locus might be considered when treating patients with LN triggered by exogenous agents.

\section{Sule Yavuz $\odot$, ${ }^{1}$ Matteo Bianchi, ${ }^{2}$ Sergey Kozyrev, ${ }^{2}$ Karin Bolin, ${ }^{1}$ Dag Leonard, ${ }^{1}$ Pascal Pucholt, ${ }^{1}$ Johanna K Sandling $\odot 1,3$ \\ Anders Bengtsson, ${ }^{4}$ Andreas Jönsen, ${ }^{4}$ Solbritt Rantapää-Dahlqvist, ${ }^{5}$ Christopher Sjöwall $\odot{ }^{6}$ Elisabet Svenungsson $\odot,{ }^{7}$ Iva Gunnarsson, ${ }^{7}$ Kerstin Lindblad-Toh, ${ }^{8}$ Lars Rönnblom ${ }^{1}$}

${ }^{1}$ Department of Medical Sciences and Rheumatology, Uppsala University, Uppsala, Sweden

${ }^{2}$ Science for Life Laboratory, Department of Medical Biochemistry and Microbiology, Uppsala University, Science for Life Laboratory, Uppsala, Sweden

${ }^{3}$ Medical Sciences and Science for Life Laboratory, Uppsala University, Uppsala,

Sweden

${ }^{4}$ Section of Rheumatology, Department of Clinical Sciences, Lund University, Lund,

Sweden

${ }^{5}$ Department of Public Health and Clinical Medicine/Rheumatology, Umeå University, Umeå, Sweden

${ }^{6}$ Clinical and Experimental Medicine, Rheumatology/AIR, Linköping, Sweden ${ }^{7}$ Department of Medicine Solna, Rheumatology Unit, Karolinska Institutet, Stockholm, Sweden

${ }^{8}$ Science for Life Laboratory, Department of Medical Biochemistry and Microbiology, Uppsala University, Uppsala, Sweden

Table 1 Clinical characteristics of patients with lupus nephritis carrying TLR1 minor allele (rs142003616)

\begin{tabular}{|c|c|c|c|c|c|c|c|c|c|c|c|c|c|c|c|c|c|}
\hline Patient & Gender & $\begin{array}{l}\text { Age at } \\
\text { diagnosis }\end{array}$ & $\begin{array}{l}\text { European } \\
\text { descent }\end{array}$ & ACR 1 & ACR 2 & ACR 3 & ACR 4 & ACR 5 & ACR 6 & ACR 7 & ACR 8 & ACR 9 & ACR 10 & ACR 11 & AutoAbs* & $\begin{array}{l}\text { Biopsy } \\
\text { ever }\end{array}$ & $\begin{array}{l}\text { WHO- } \\
\text { classt }\end{array}$ \\
\hline 1 & $\mathrm{~F}$ & 16 & Yes & Yes & No & No & No & Yes & No & Yes & No & No & Yes & Yes & $Y: N: N$ & No & - \\
\hline 2 & $\mathrm{~F}$ & 26 & Yes & Yes & No & Yes & No & Yes & No & Yes & No & Yes & Yes & Yes & $Y: Y: N$ & No & - \\
\hline 3 & $\mathrm{~F}$ & 16 & Yes & Yes & No & Yes & Yes & Yes & Yes & Yes & Yes & No & No & Yes & $\mathrm{N}: \mathrm{N}: \mathrm{N}$ & Yes & Unknown \\
\hline 4 & $\mathrm{~F}$ & 53 & Yes & Yes & Yes & Yes & No & Yes & No & Yes & Yes & No & No & Yes & $\mathrm{N}: \mathrm{N}: \mathrm{Y}$ & Yes & v \\
\hline 5 & $\mathrm{~F}$ & 15 & Yes & Yes & No & No & No & Yes & No & Yes & No & Yes & Yes & Yes & Y:N:N & Yes & IV d \\
\hline $6 \neq$ & $\mathrm{F}$ & 39 & Yes & No & No & No & No & No & No & Yes & No & Yes & Yes & Yes & $Y: N: Y$ & Yes & $\mathrm{Vb}$ \\
\hline
\end{tabular}


Correspondence to Professor Sule Yavuz, Department of Medical Sciences and Rheumatology, Uppsala Universitet, Uppsala 75185, Sweden; sule.yavuz@medsci.uu.se

\section{Handling editor Josef S Smolen}

Contributors SY, KL-T, JKS and LR conceived and designed the study. SK ran the experiments. AB, AJ, IG, ES, SR-D, CS and DL provided samples. SY, KB acquired data. The statistical analysis was conducted by MB, PP, SY. The interpretation of data was made by SY, IG, and LR and SY drafted the manuscript. All authors revised the article for important intellectual content and approved the final version for publication.

Funding This study was funded by the Swedish Rheumatism Association and King Gustav V's 80-year Foundation, Uppsala Universitet, the Swedish Society of Medicine and the Ingegerd Johansson donation, Swedish Research Council for Medicine and Health.

Competing interests None declared.

Patient and public involvement Patients and/or the public were not involved in the design, or conduct, or reporting, or dissemination plans of this research.

Patient consent for publication Obtained.

Provenance and peer review Not commissioned; externally peer reviewed.$$
\text { (2) }
$$$$
\text { OPEN ACCESS }
$$

Open access This is an open access article distributed in accordance with the Creative Commons Attribution Non Commercial (CC BY-NC 4.0) license, which permits others to distribute, remix, adapt, build upon this work non-commercially, and license their derivative works on different terms, provided the original work is properly cited, appropriate credit is given, any changes made indicated, and the use is non-commercial. See: http://creativecommons.org/licenses/by-nc/4.0/.

(C) Author(s) (or their employer(s)) 2021. Re-use permitted under CC BY-NC. No commercial re-use. See rights and permissions. Published by BMJ.

- Additional material is published online only. To view please visit the journal online (http://dx.doi.org/10.1136/annrheumdis-2020-218373).

\section{(A) Check for updates}

To cite Yavuz S, Bianchi M, Kozyrev S, et al. Ann Rheum Dis 2021;80:404-406.

Received 24 June 2020

Revised 31 July 2020

Accepted 9 August 2020

Published Online First 29 September 2020

Ann Rheum Dis 2021;80:404-406. doi:10.1136/annrheumdis-2020-218373

\section{ORCID iDs}

Sule Yavuz http://orcid.org/0000-0001-5053-6426

Johanna K Sandling http://orcid.org/0000-0003-1382-2321

Christopher Sjöwall http://orcid.org/0000-0003-0900-2048

Elisabet Svenungsson http://orcid.org/0000-0003-3396-3244

\section{REFERENCES}

1 Devarapu SK, Anders H-J. Toll-Like receptors in lupus nephritis. J Biomed Sci 2018;25:35.

2 Thomas-Chollier M, Hufton A, Heinig M, et al. Transcription factor binding predictions using trap for the analysis of ChIP-Seq data and regulatory SNPs. Nat Protoc 2011;6:1860-9.

3 Alarcón-Riquelme ME. Role of Runx in autoimmune diseases linking rheumatoid arthritis, psoriasis and lupus. Arthritis Res Ther 2004:6:169-73.

4 Reid $\mathrm{S}$, Alexsson A, Frodlund $\mathrm{M}$, et al. High genetic risk score is associated with early disease onset, damage accrual and decreased survival in systemic lupus erythematosus. Ann Rheum Dis 2020;79:363-9.

5 Bhargava R, Tsokos GC. The immune podocyte. Curr Opin Rheumatol 2019;31:167-74.

6 Gurkan S, Cabinian A, Lopez V, et al. Inhibition of type I interferon signalling prevents TLR ligand-mediated proteinuria. J Pathol 2013;231:248-56.

7 Tan EM, Cohen AS, Fries JF, et al. The 1982 revised criteria for the classification of systemic lupus erythematosus. Arthritis Rheum 1982;25:1271-7.

8 Hochberg MC. Updating the American College of Rheumatology revised criteria for the classification of systemic lupus erythematosus. Arthritis Rheum 1997;40:1725.
9 Bolin K, Sandling JK, Zickert A, et al. Association of STAT4 polymorphism with severe renal insufficiency in lupus nephritis. PLoS One 2013;8:e84450. 